\title{
Effect of Tower Construction Analysis Against Reliability Level of SUTET 500kV to Lightning Strike
}

\author{
Riza Alfita ${ }^{1}$, Musa Abdul Basith ${ }^{2}$, Diana Rahmawati ${ }^{3}$, Rosida Vivin Nahari ${ }^{4}$, Kunto Aji Wibisono ${ }^{5}$. \\ Achmad Fiqhi Ibadillah ${ }^{6}$, Mirza Pramudia ${ }^{7}$ \\ Faculty of Engineering \\ University of Trunojoyo Madura \\ Bangkalan, Indonesia \\ ${ }^{1}$ riza.alfita@trunojoyo.ac.id, ${ }^{2}$ musaabdulbasith@gmail.com, ${ }^{3}$ diana_rahmawti@yahoo.com, ${ }^{4}$ rosida.nahari@trunojoyo.ac.id; \\ ${ }^{5}$ kunto.elektro@gmail.com; ${ }^{6}$ fiqhi.achmad@gmail.com, ${ }^{7}$ mirza_ub@yahoo.com
}

\begin{abstract}
The Extra High Voltage Air Line (SUTET) is a transmission line conductor with a voltage of $500 \mathrm{kV}$ which aims to deliver electrical energy from the plant to the load center, so that electrical energy can be efficiently discharged. The gap between the distant towers and the different tower construction causes the transmission channel's insignificance. Unreliable tower lines can cause channel outages and damage to existing equipment in the tower. It is necessary to construct effective and efficient transmission line tower types because of the expensive cost of repair and maintenance. So that, the transmission line performance can work reliably. Furthermore, software is needed to analyze the effect of tower construction on the reliability level of SUTET $500 \mathrm{kV}$ to the lightning strike using the waves running method. The software existence can be used to calculate the lightning disturbance that occurs in the tower with various types of construction in Indonesia. Also, this research results contribute to the continuity of electricity system services in Indonesia.
\end{abstract}

Keywords- electrical system; lightning strike; Extra High Voltage Air Line component;

\section{INTRODUCTION}

Transmission towers have the very important role in the process of distributing electrical energy from one place to another. This is due to the increasingly modern and sophisticated era so that the need for increased electrical energy in the industrial sector or the needs of society at this time. The increasing need for electrical energy must be followed by a high quality electrical energy system and has a high reliability, the principle in the transmission of electrical energy is both safe and economical. With the transmission tower, it is necessary to construct a specific transmission tower so that the need to distribute electrical energy is not hampered due to the damage of the transmission tower[1].

Disturbances that occur in the transmission tower construction one of them caused by lightning strikes. The occurrence of such damage can lead to the main components work is not in accordance with their needs resulting in failure of protection or damage to electrical construction networks that affect the transmission line. That means the reliability of a power system is determined by the ability of the system to supply sufficient electrical energy to the consumer. So, this system must be reliable and meet the requirements to be able to reduce the sudden disruption caused by lightning strikes [2].

Transmission networks in Indonesia are more dominant using airways when compared to underground channels, because the transmission network in the manufacture more economical, easy to reach and cheap operational costs. In addition, the current electric power system is an interconnection system between one power plant and another with a purpose if either one of the power plant or transmission line is interrupted, the supply of electricity can still run. Another problem with the airways is the frequent interference with the main components. Indonesia conditions that have a tropical climate often happens lightning strikes and it is enough to make the transmission system is potentially struck by lightning. In addition, the use of airways that have different tower construction and different tower height coordinates has become one of the factors affected by lightning strikes [3-7].

Video surveillance for transmission lines, which can record the man-made destroying, foreign objects attaching to the lines, swing of the lines, conductor icing, etc. [8]

Therefore, to obtain reliable and sustainable power distribution, it is necessary to analyze the effect of tower construction on the reliability level of $500 \mathrm{kV}$ SUTET to the lightning strike to produce the modeling result and the software that can be applied to facilitate the design automatically.

The remainder of this paper is organized as follows: an analysis calculation of the flash interference in the tower on transmission sytem is presented in Section 2. In Section 3 software trial is addressed. Finally, some conclusions are shed.

\section{RESEARCH METHODOLOGY}

To perform this analysis calculation using the current wave method to obtain a negative reflection wave so that almost all of the flashback / backflashover occurs at the top of the phase wire so as to calculate the flash interference in the tower[3]

With case studies on Krian Substation in 2018, the main part of this method will be discussed as follows: 
1. Disturbance at construction height of different tower.

To obtain the angle of ground wire protection in the construction of AA type Tower and CC type, so it can be calculated:

$$
\begin{aligned}
& x=\sqrt{(L)^{2}+(H)^{2}} \\
& \sin \theta=\frac{L}{x} \\
& \theta=\sin ^{-1} \Xi
\end{aligned}
$$

Lightning failure on phase wire

$$
\mathrm{D}=8,875 \cdot 10^{-8} \xi \mathrm{IK} \Lambda
$$

Where the value of $\mathrm{D}$ is to obtain lightning density per square meter per year by entering IsoKeraunik Level (IKL)

$$
\mathrm{A}=(2 \pi+1) \mathrm{Ht}^{2}+4 H g(S-H t)
$$

Where the value of $\mathrm{A}$ is the area of protected area ground wire with meter $^{2}$ unit.

$$
\mathrm{L}=100 \cdot \frac{1000}{s} \cdot \mathrm{A} \cdot \Delta
$$

The L value represents the lightest amount of lightning that may occur in the transmission tower.

$$
\log P \theta=\frac{\theta \sqrt{H t}}{90}-4
$$

$P \theta$ represents the probability of failure of ground wire protection.

$$
\Sigma \Phi O=P \theta \cdot L
$$

The value of SFO is the amount of lightning disturbance on the phase wire per $100 \mathrm{~km}$ of introduction per year due to the failure of ground wire protection in each tower construction [3].

2. To get the value of interference on the construction line of Tower of Krian - Gresik, it is necessary picture of transmission tower and its shadow wire [3][6] :

$$
\begin{gathered}
\alpha_{1}=\sqrt{h_{t p}{ }^{2}+\left(\frac{1}{2} c-\frac{1}{2} a_{12}\right)^{2}} \\
\alpha_{2}=\sqrt{h_{t p}{ }^{2}+\left[a_{12}+\left(\frac{1}{2} c-\frac{1}{2} a_{12}\right)\right]^{2}} \\
\alpha_{1} \square=\sqrt{\left(2 h_{t}-h_{t p}\right)^{2}+\left(\frac{1}{2} c-\frac{1}{2} a_{12}\right)^{2}}
\end{gathered}
$$

$$
\alpha_{2}=\sqrt{\left(2 h_{t}-h_{t p}\right)^{2}+\left[a_{12}\left(\frac{1}{2} c-\frac{1}{2} a_{12}\right)\right]^{2}}
$$

Where the value of

$$
\begin{aligned}
& \mathrm{a}_{1}: \text { the distance between ground wire } 1 \text { and phase } 1 \text { wire } \\
& \mathrm{a}_{2}: \text { the distance between the ground wire } 2 \text { and the phase } \\
& \text { wire } 1 \\
& \mathrm{a}_{1}, \quad: \text { the distance between the ground wire } 1 \text { and the phase } \\
& \text { shadow wire } 1 \\
& \mathrm{a}_{2} \text { ': the distance between the ground wire } 2 \text { and the shadow } \\
& \text { phase wire. }
\end{aligned}
$$

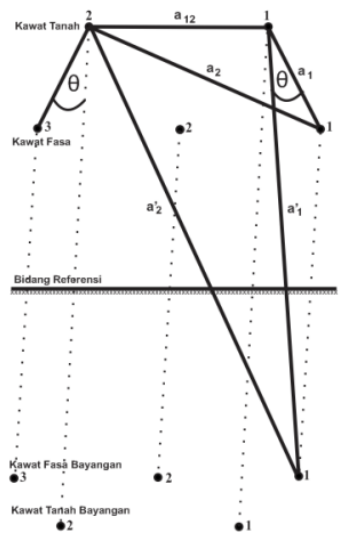

Fig. 1. The transmission structure and the shadow wire

$$
\mathrm{K}=\frac{\ln \sqrt{\frac{\left(a 1^{\prime} \cdot a 2^{\prime}\right)}{a 1 \cdot a 2}}}{\ln \left(\frac{2 h g}{\sqrt{a 12 r}}\right)}
$$

The value of $\mathrm{K}$ is the Clutch factor by entering the values obtained in the previous formula

$$
Z_{g}=60 \ln \left(\frac{2 h_{g}}{a_{12} r}\right)
$$

The $Z_{g}$ value is the result of a ground wire impedance

$$
\begin{gathered}
\ln R_{t}=\frac{h_{o}}{h_{t}\left(x_{b}-x_{u}\right)}\left[x_{b}\left(\ln x_{b}-0,87\right)-\right. \\
\left.x_{u}\left(\ln x_{u} 0,87\right)\right]+\frac{h_{t}-h_{o}}{h_{t}} \ln \left(1,14 x_{u}\right)
\end{gathered}
$$

The Rt value is the equivalent radius of the Tower by changing the value of the meter unit to the leg unit and the final result is converted back into meters.

$$
Z_{t}=60 \ln \left(\sqrt{2} \frac{2 h_{t}}{r_{t}}\right)-60
$$

The value of $Z_{t}$ is the impedance value of the TransmissionTower.

$$
\alpha=\frac{2 \cdot \mathrm{Zg}}{Z g+2 . Z t}
$$




$$
\beta=\alpha \square 1
$$

Calculates the transmission coefficient (a) at the top of the tower for the waves coming from the bottom of the tower. Which is used to find the reflection coefficient (b) at the top of the tower for the waves coming from the base of the tower.

$$
\varepsilon=\frac{2 \cdot \mathrm{Zg}}{Z g+Z t} \mathrm{I} \sigma
$$

$\mathrm{e}$ is the peak voltage of the tower with the peak current value (Is) $=60$.

$$
\delta=\frac{R f-\mathrm{Rt}}{R f+R t}
$$

The value of the reflection coefficient (d) at the base of the tower is used to calculate the waves coming from the top of the tower

$$
\left\langle=\frac{2 . Z g}{Z g+2 . Z t}\right.
$$

The value of $\alpha$ is used to find the transmission coefficient at the top of the Tower for the incoming wave.

$$
\begin{gathered}
V=K_{1} \cdot W \frac{K_{2} \cdot W}{t^{0,75}} \\
V_{50 \%}=\left(1+e^{\frac{t}{T}}\right)+V
\end{gathered}
$$

The value of $V_{50 \%}$ is the impulse voltage of the tower voltage $(\mathrm{V})$ with the lightning advance time $(\mathrm{t})=0.5 \mu \mathrm{s}$.

$$
\tau_{\chi}=\tau+\frac{X 1}{c}
$$

Tc is the time when the peak voltage drops suddenly due to the reflection wave (critical time) with the value of the crosssectional area of the conductor $(c)=300$.

$$
\mathrm{E}_{0}=\left(\frac{\mathrm{Zg} \cdot \mathrm{Zt}}{Z g+2 \cdot Z t} \mathrm{I}_{0}\right) / \tau
$$

The value of $e_{0}$ is the initial stress of the top of the Tower

$$
\begin{gathered}
V i=e_{0}(1-k) \cdot\left(t_{c} \frac{X_{1}}{C}\right)+d \cdot e_{0}\left(t_{c}-\frac{2 h_{t}-X_{1}}{C}\right) \\
+d \cdot e_{0}(b-K)\left(t_{c}-\frac{2 h_{t}-X_{1}}{C}\right)+d^{2} \cdot b \cdot e_{0} \\
\left(t_{c}-\frac{4 h_{t}-X_{1}}{C}\right)+d^{2} \cdot b \cdot e_{0}(b-K a) \\
\left(t_{c}-\frac{4 h_{t}-X_{1}}{C}\right)+d^{3} \cdot b^{2} \cdot e_{0}\left(t_{c}-\frac{6 h_{t}-X_{1}}{C}\right)
\end{gathered}
$$

$+d^{3} \cdot b^{2} \cdot(\mathrm{b}-\mathrm{Ka})\left(t_{c}-\frac{6 h_{t}-X_{1}}{C}\right)$

$V i$ is the isolator voltage by inputting the input value in the previous result.

$$
\Pi_{0}=\mathrm{E}_{0}: V_{i}
$$

The value of $\mathrm{P}_{0}$ is the peak value of a certain lightning current.

$$
\begin{aligned}
& (P i \%)=\sum P \times \sum \frac{\text { flicker failure }}{\text { flicker's quantity }} \\
& (Q i \%)=\sum Q j \times \sum \frac{\text { pounced time }}{\text { amount of time }}
\end{aligned}
$$

The $P$ value is the number of possible flashes. By entering the value of percentage $\mathrm{Pi}$ and the percentage of the possibility of a certain lightning current wave advance time $(\mathrm{Qj})$.

$$
0_{t}=60 \% \times L \times P
$$

$\mathrm{O}_{\mathrm{t}}$ is the number of lightning disturbances in the transmission tower channel.

\section{RESUlT AND DISCUSSION}

Software testing is divided into two outputs, the first is to analyze the height difference of tower construction on the lightning strike and the second to analyze the tower line Krian Gresik. Fig. 1 below shows AA Suspension Tower and Fig. 2 describes Tower of Tention CC.

A. Interference at height construction of different tower.

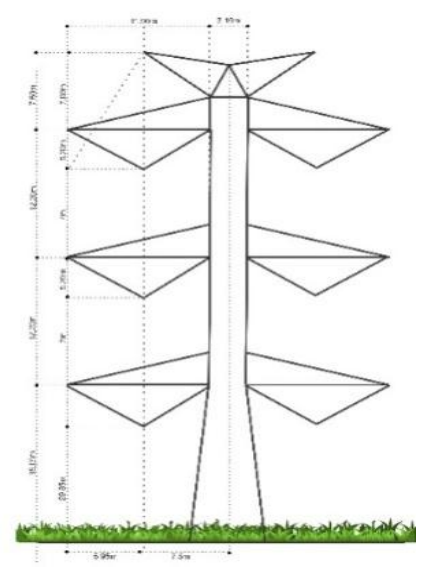

Fig. 2. AA Suspension Tower 


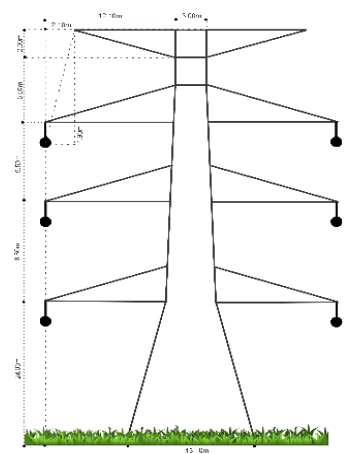

Fig. 3. Tower of Tention CC

TABle I. The ANgle Of Shielding Based On The Height Of The GROUND WIRE AGAINST THE PHASE WIRE

\begin{tabular}{|c|c|c|c|c|c|c|}
\hline Pilar & Type & $\begin{array}{c}\text { Height } \\
\text { Top }\end{array}$ & $\mathbf{L}$ & $\mathbf{X}$ & $\operatorname{Sin} \boldsymbol{\theta}$ & $\boldsymbol{\theta}$ \\
\hline T.15 & CC+3 & 14,4 & 2,10 & 15,641 & 0.1342 & $7,71^{\circ}$ \\
\hline T.16 & AA+3 & 15.8 & 5.95 & 16.883 & 0.3524 & $20,63^{\circ}$ \\
\hline T.17 & AA+0 & 12.8 & 5.95 & 14.115 & 0.4215 & $24,93^{\circ}$ \\
\hline T.18 & AA-3 & 12.8 & 5.95 & 14.115 & 0.4215 & $24,93^{\circ}$ \\
\hline T.19 & AA+0 & 12.8 & 5.95 & 14.115 & 0.4215 & $24,93^{\circ}$ \\
\hline
\end{tabular}

In Table 1. Tower Pillar no. 15-19 have different shooting angles due to variations in the high phase wire addition. By obtaining a varying angle it can calculate the flash interruption in each Tower construction [5].

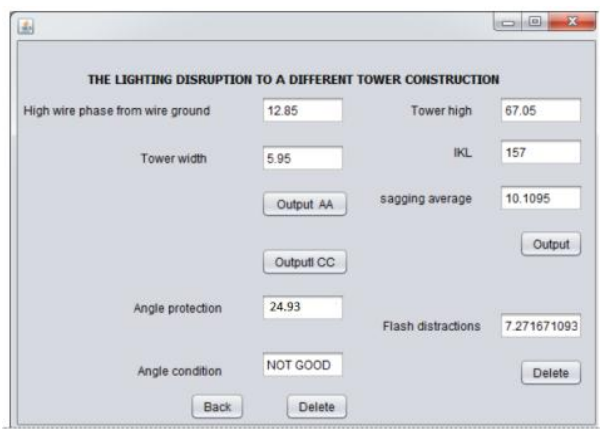

Fig. 4. Results of the program on the AA tower

\section{B. AA Suspension Tower}

Fig. 4 above shows that a protection angle of $24.93^{\circ}$. On the angle of shield A suspension tower is considered not good because according to Provoost theory in 1960 it suggested a good shielding state of the transmission tower if it is less than $18^{\circ}$ angle [5].

After obtaining the angle of protection it can calculate the value of lightning disturbance in the tower by using formula (8) and obtain the result of 74027 interruption [3].

\section{CC Tension Tower}

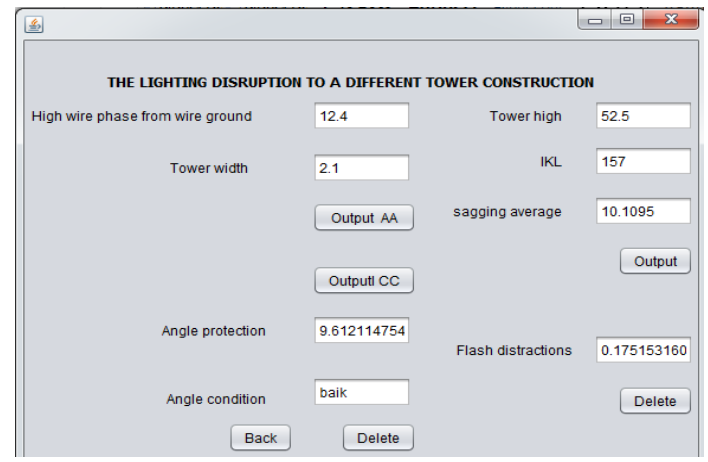

Fig. 5. Program Results on CC Type Tower

Fig. 5 above obtain a protection angle of $9.61^{\circ}$. at the angle of the $\mathrm{CC}$ suspension tower shell is considered good because according to the Provoost theory in 1960 it suggests a good shielding state of the transmission tower if it is less than $18^{\circ}$ angle. By performing the calculation of the formula (6) then obtaining a lightning distortion value of 0.1751 disorder [3].

\section{Disturbance on the line of transmission tower Krian-}

Gresik.

Average disturbance in the queue - gresik line using the AA tower type suspension. With $+0(\mathrm{AA}+0)$ tower height. In the formula (24) with the critical time (t) 0.5 and the critical current (Io) 60 then obtained:

TABLE II. TIME OF CRITICAL VOLTAGE

\begin{tabular}{|c|c|}
\hline Time $\mathbf{t}(\boldsymbol{\mu}$ second) & $\begin{array}{c}\text { Critical voltage }(t c) \\
\text { time }\end{array}$ \\
\hline 0.5 & 0.5366 \\
\hline 1 & 1.0366 \\
\hline 1.5 & 1.5366 \\
\hline 2 & 2.0366 \\
\hline 2.5 & 2.5366 \\
\hline
\end{tabular}

In table II, inserting different input $(\mathrm{t})$ will produce different critical voltage (tc) time.

TABLE III. TOWER PEAK VOLTAGE

\begin{tabular}{|c|l|r|}
\hline $\mathbf{t}(\boldsymbol{\mu}$ second $)$ & $\mathbf{I}_{\mathbf{0}}(\mathbf{k A})$ & $\mathbf{E}_{\mathbf{0}}(\mathbf{k V})$ \\
\hline 0,5 & 60 & 12265.7297 \\
\hline 0,5 & 120 & 24534.6023 \\
\hline 0,5 & 180 & 36801.9035 \\
\hline 0,5 & 220 & 44980.1042 \\
\hline 1 & 60 & 6133.6505 \\
\hline 1 & 120 & 12267.3011 \\
\hline 1 & 180 & 18400.9517 \\
\hline 1 & 220 & 22490.0521 \\
\hline 1,5 & 60 & 4089.1003 \\
\hline 1,5 & 120 & 8178.200 \\
\hline 1,5 & 180 & 12267.3011 \\
\hline 1,5 & 220 & 14993.3680 \\
\hline 2 & 60 & 3066.8252 \\
\hline 2 & 120 & 6133.6505 \\
\hline 2 & 180 & 9200.4758 \\
\hline 2 & 220 & 11245.0260 \\
\hline
\end{tabular}


In Table III. Represents the formula (24) by producing the initial peak voltage value of Tower (E0).

In Table IV. It is a calculation step to the end. The table above is used to compare all E0 values with $V_{i}$, if the value of $\mathrm{E}_{0}<V_{i}$, then backflashover or flashover occurs. In $\mathrm{T}=1.5$, when $P_{0}=0,702$ to downwards has backflashover.

TABLE IV. VOLTAGE COMPARATOR WHEN HIT BY A STRIKE

\begin{tabular}{|c|c|c|c|c|c|}
\hline $\mathbf{T}$ & $\mathbf{t}_{\mathbf{c}}$ & $\mathbf{I}_{\mathbf{0}}$ & $\mathbf{E}_{\mathbf{0}}(\mathbf{k V})$ & $\boldsymbol{V}_{\boldsymbol{i}}(\mathbf{k V})$ & $\begin{array}{c}\mathbf{E}_{\mathbf{0}} \boldsymbol{V}_{\boldsymbol{i}} \\
\left(\boldsymbol{P}_{\mathbf{0}}\right)\end{array}$ \\
\hline 0,5 & 0,536 & 60 & 12265.729 & 4552.158 & 2.695 \\
\hline 0,5 & 0,536 & 120 & 24534.602 & 9101.496 & 2.695 \\
\hline 0,5 & 0,536 & 180 & 36801.903 & 13652.244 & 2.695 \\
\hline 0,5 & 0,536 & 220 & 44980.104 & 16686.076 & 2.695 \\
\hline 1 & 1,036 & 60 & 6133.650 & 5505.214 & 1.114 \\
\hline 1 & 1,036 & 120 & 12267.301 & 11010.429 & 1.114 \\
\hline 1 & 1,036 & 180 & 18400.951 & 16515.644 & 1.114 \\
\hline 1 & 1,036 & 220 & 22490.052 & 20185.787 & 1.114 \\
\hline 1,5 & 1,536 & 60 & 4089.100 & 5823.370 & 0.702 \\
\hline 1,5 & 1,536 & 120 & 8178.20 & 11646.740 & 0.702 \\
\hline 1,5 & 1,536 & 180 & 12267.301 & 17470.110 & 0.702 \\
\hline 1,5 & 1,536 & 220 & 14993.368 & 21352.357 & 0.702 \\
\hline 2 & 2,036 & 60 & 3066.825 & 5982.447 & 0.512 \\
\hline 2 & 2,036 & 120 & 6133.650 & 1196.8954 & 0.512 \\
\hline 2 & 2,036 & 180 & 9200.475 & 17947.343 & 0.512 \\
\hline 2 & 2,036 & 220 & 11245.026 & 21935.642 & 0.512 \\
\hline
\end{tabular}

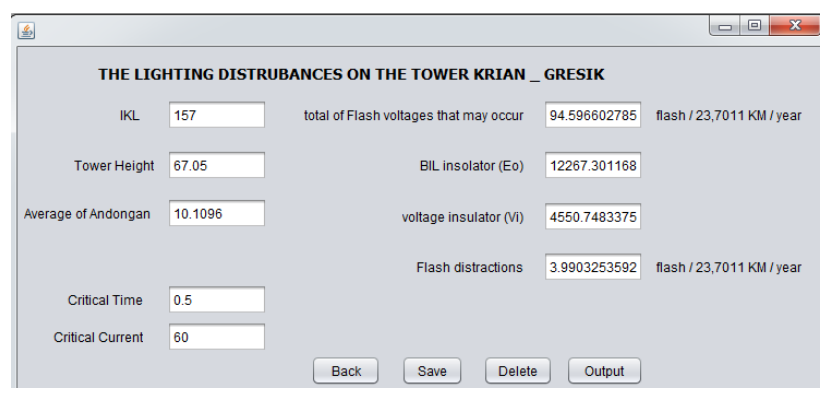

Fig. 6. Calculation results of channel interference.

Fig. 6 above points out the final result of the disturbance calculation with a disturbance value of 3.9903 flash / 23.7011 $\mathrm{km}$ per year.

\section{CONCLUSION AND FURTHER RESEARCH}

From the result of this result analysis can be concluded that:

1. On Suspension AA transmission towers get $24.93^{\circ}$ angle protection with 74027 flash disturbance and CC tention tower obtains $9.6121^{\circ}$ angle protection with 0,175 lightning disturbance. So, this is more effective using CC tension tower.

2. The calculation of lightning disturbance in the Krian Gresik line is 3,990 flash / $237011 \mathrm{~km}$, per year is in accordance with existing data from PLN.

3. In lightning disturbance of transmission towers apart from being influenced by different tower constructions are also influenced by the number of days of thunder (IKL)

The results of research on the development of lightning outage application software to detect the Reliability of $500 \mathrm{kV}$ Extra High Voltage Air Channels to lightning strikes can contribute directly to the public because it concerns the continuity of electrical system services in Indonesia. Our further research will be development of lightning outage application software to detect the reliability of 1 MV Extra High Voltage Air Channels.

\section{ACKNOWLEDGMENT}

We would like to thank our colleagues at University of Trunojoyo, Madura, Indonesia, particularly Faculty of Engineering for all supports. Thank you very much also goes to the reviewers for the constructive feedback for improving the quality of this paper.

\section{REFERENCE}

[1] M. R. Iryani and N. A. Kadir, "Lighting study and experience on the first $500 \mathrm{kV}$ Transmision line Arrester in Malaysia", Shanghai, China, International Conference on Lighting Protection (ICLP) vol. 978, no. 1, pp. 4799-3544, 2014.

[2] S. P. Gopi, "Analisys and Design of Transmission Tower", International Journal Of Modern Engineering Research (IJMER), vol. 4, no. 1, pp. 116138,1987

[3] R. Zoro, "Protection Against Over Voltage In Electric Power Systems", Institut Teknologi Bandung, 2014.

[4] Ikbal, "Recovery Voltage On High Voltage Breaking Contacts For Protection Against Waves", Blitar,.p-ISSN:2088-424; eISSN: 2527-3892, 2018

[5] P. S. Harijanto and R. Zoro, "Analysis of lightning strike to overhead EHV $500 \mathrm{KV}$ transmission system Jawa-Bali Crossing". InPower Engineering and Renewable Energy (ICPERE), 3rd Conference on 2016 Nov 29, pp. 275-280, 2016

[6] R. Alfita, M. Choirudin, R. V. Nahari, K. Kartika, "Analysis of Power Outage Software for $500 \mathrm{kV}$ Extra High Voltage Air Channels Against Lightning Strikes". In Seminar Nasional Inovasi Teknologi 2017 Feb 22, Vol. 1, No. 1, pp. 069-074, 2017.

[7] R. Alfita, et al, "Implementation of Fuzzy Sugeno Method for Power Efficiency". International Journal of Advanced Engineering Research and Science (ISSN : 2349-6495(P) | 2456-1908(O)), vol 4, no. 9, pp.001-005, 2017.

[8] L. Yuan, and H. Gao, "Video Surveillance System for Extra-high Voltage Power Transmission Lines with an Optimal Image 1 Compression Method", ICCEM, pp.42-55, 2015. 